\title{
Bioactive Oligostilbenoids from the Stem Bark of Hopea
}

\author{
exalata
}

\author{
Hui Ming Ge, Bo Huang, Shu Hua Tan, Da Hua Shi, Yong Chun Song, and Ren Xiang Tan* \\ Institute of Functional Biomolecules, State Key Laboratory of Pharmaceutical Biotechnology, Nanjing \\ University, Nanjing 210093, People's Republic of China
}

Scheme S1. Biogenetic pathway for 1

Figure S1. ${ }^{1} \mathrm{H}$ NMR spectrum $\left(300 \mathrm{MHz}\right.$, acetone- $\left.d_{6}\right)$ of compound 1

Figure S2. ${ }^{13} \mathrm{C}$ NMR spectrum $\left(75 \mathrm{MHz}\right.$, acetone- $\left.d_{6}\right)$ of compound 1

Figure S3. Selected HMBC correlations of compound 1

Figure S4. Time-course inhibition of jack bean urease activity by compound 2 and AHA

\footnotetext{
*To whom correspondence should be addressed. Tel: +86-25-8359 2945. Fax: +86-25-8330 2728. E-mail: rxtan@nju.edu.cn.
} 


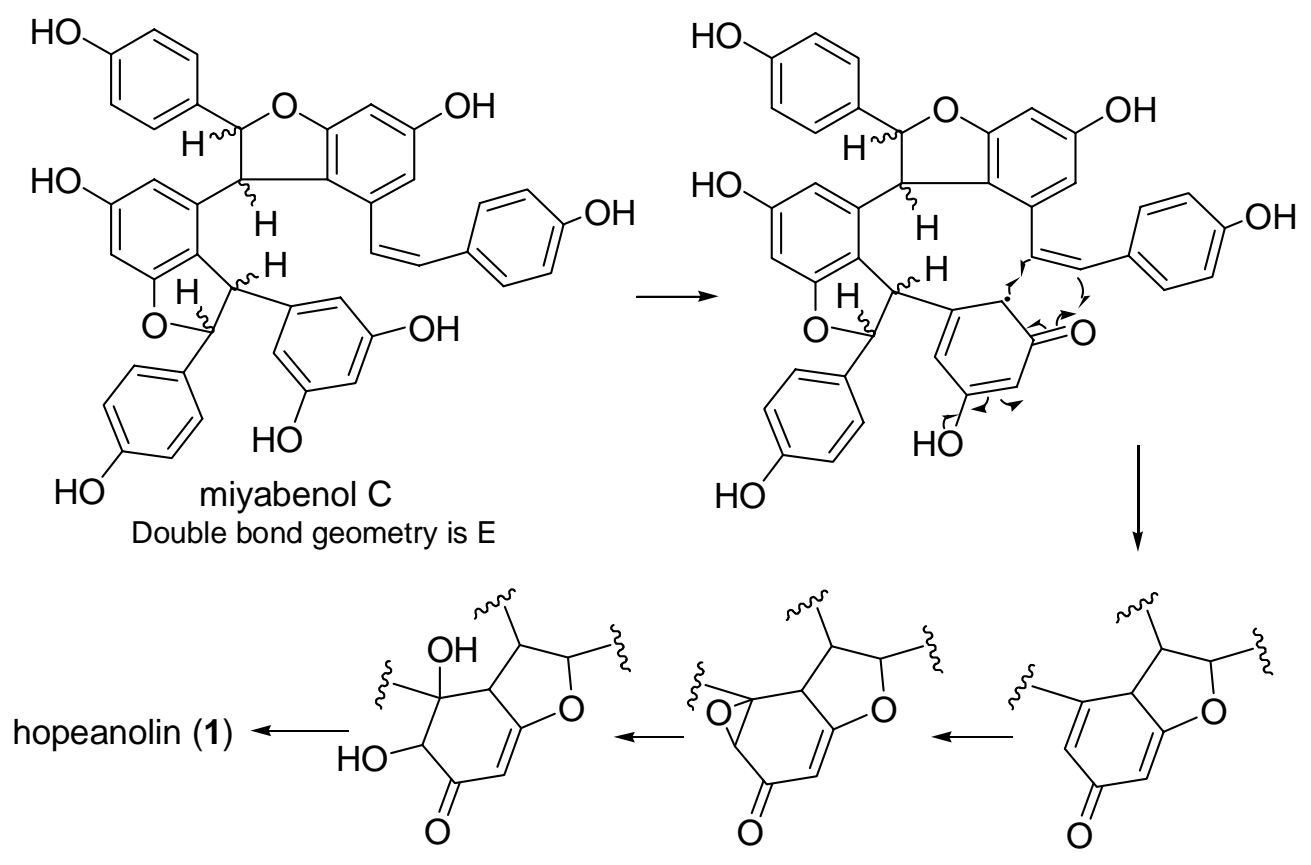

Scheme S1. Biogenetic pathway for 1 


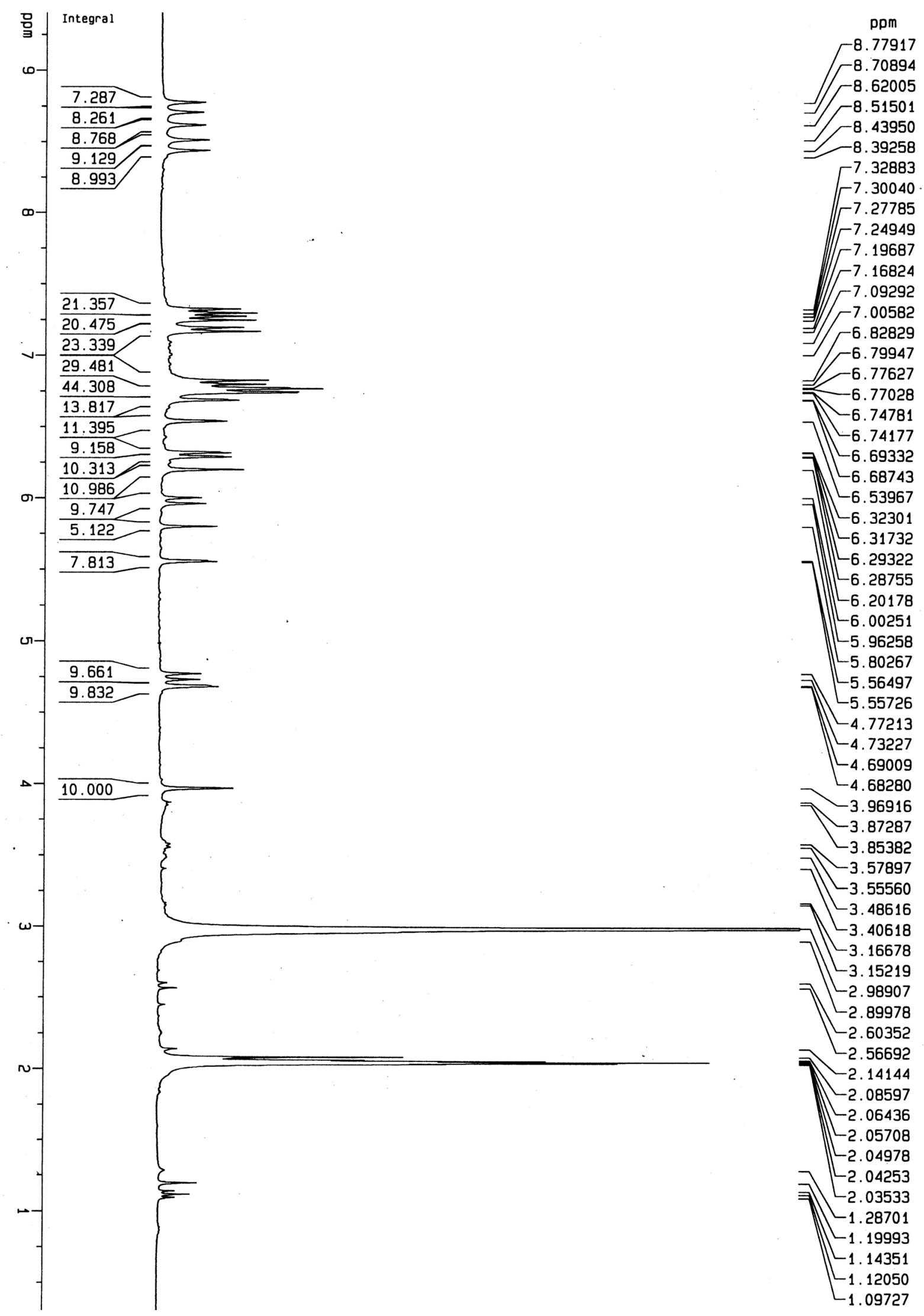

Figure S1. ${ }^{1} \mathrm{H}$ NMR spectrum $\left(300 \mathrm{MHz}\right.$, acetone- $\left.d_{6}\right)$ of compound $\mathbf{1}$ 


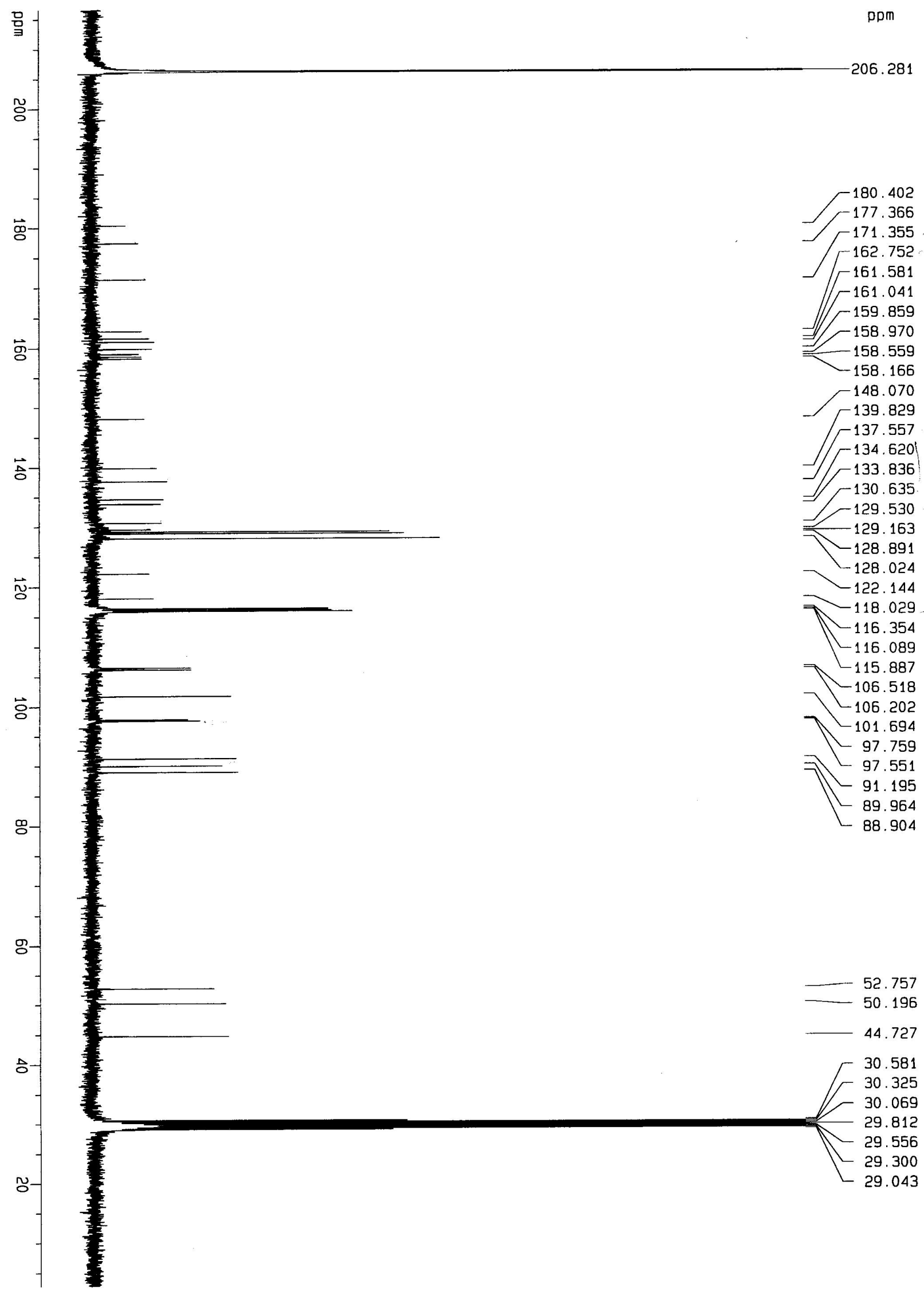

Figure S2. ${ }^{13} \mathrm{C}$ NMR spectrum (75 MHz, acetone- $d_{6}$ ) of compound $\mathbf{1}$ 


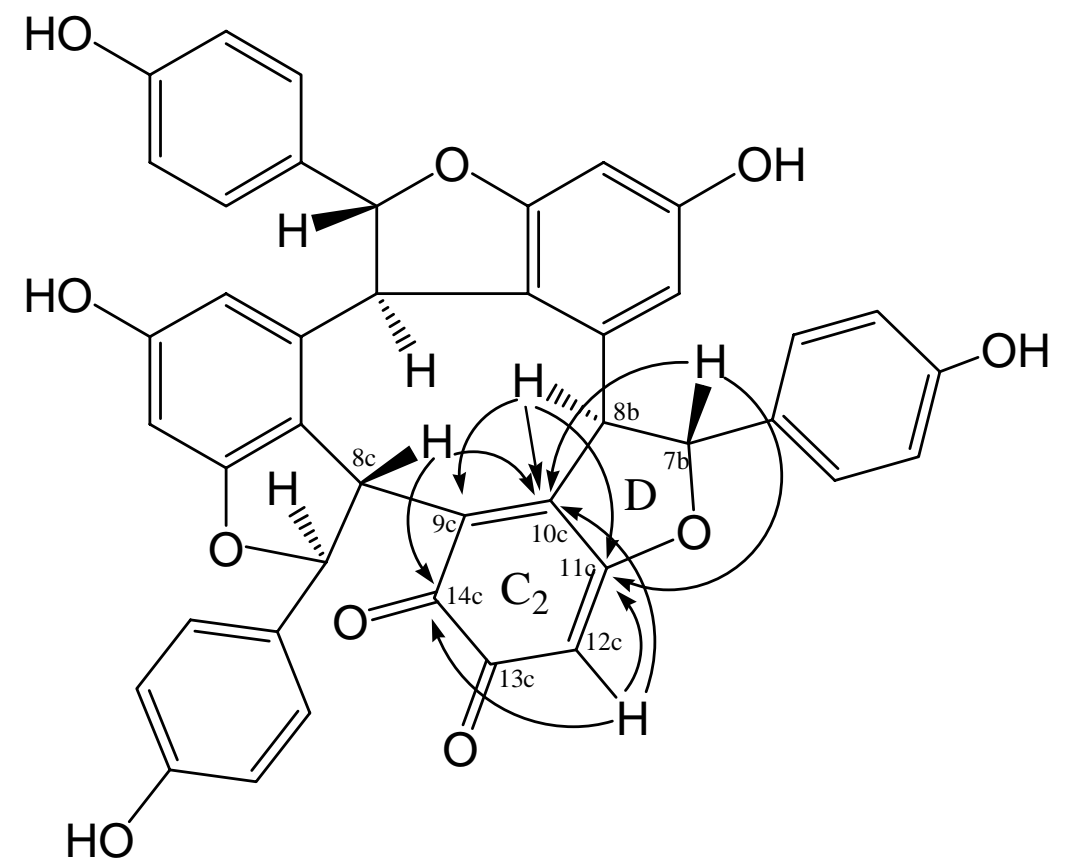

Figure S3. Selected HMBC correlations of compound 1 


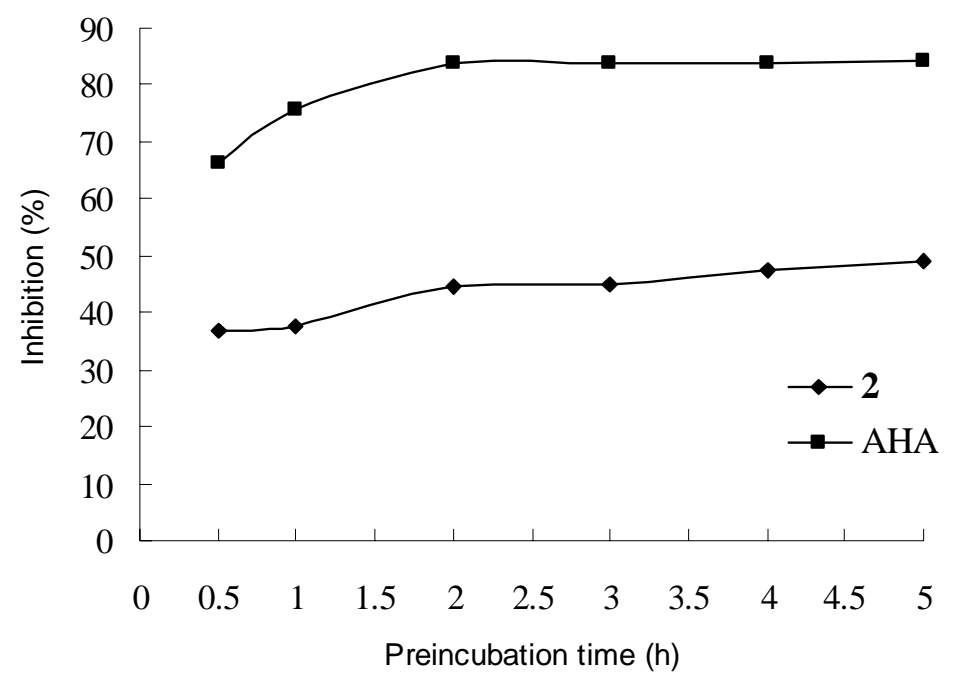

Figure S4. Time-course inhibition of jack bean urease activity by compound $\mathbf{2}$ and AHA 